(c) American Dairy Science Association, 2004.

\title{
Evaluation of Mozzarella Cheese Stretchability by the Ring-and-Ball Method
}

\author{
Z. Hicsasmaz, L. Shippelt, and S. S. H. Rizvi \\ Institute of Food Science, Cornell University, \\ Stocking Hall, Ithaca, NY 14853
}

\begin{abstract}
The functional quality of Mozzarella cheese is defined by its ability to melt and stretch. Currently used methods to evaluate the stretchability of Mozzarella cheese are empirical and lack control of moisture loss and temperature. The typical fork test, the imitative tensile stretch test, and the 3-pronged-hook probe tensile test all expose the test samples to ambient conditions during stretching and thus give poorly reproducible results. An objective method developed in our laboratory to evaluate stretchability of cheese is based on the principle of the Ring-and-Ball method used to measure the softening point of polymers. This technique, which controls temperature and moisture loss, was used to quantify the stretchability of Mozzarella cheese. Average stretch length varied between 4 to $9 \mathrm{~cm}$ between the youngest and the oldest cheese samples. The method was found to be sensitive enough to discriminate between cheeses of different ages. The results showed that the technique is reproducible and gives reliable stretch length and stretch length vs. time data, which was further used to estimate extensional viscosity of the test sample. Agerelated differences were reflected in extensional viscosity that decreased from 17.4 to $13.6 \mathrm{kPa} \cdot \mathrm{s}$ with increase in age.
\end{abstract}

(Key words: Mozzarella, stretchability, extensional viscosity)

\section{INTRODUCTION}

Mozzarella cheese production has increased steadily for the last $20 \mathrm{yr}$, and its consumption has increased from $7 \mathrm{lbs}$ per person in 1981 to almost $10 \mathrm{lbs}$ per person in 2001 (IDFA, 2002). The low-moisture, part-skim Mozzarella cheese holds the highest share in Mozzarella production and is mainly used as a pizza topping (Kinstedt, 1993). This use has prompted the industry to find new ways of making high-quality Mozzarella

Received November 5, 2003

Accepted January 30, 2004.

Corresponding author: S. S. H. Rizvi; e-mail: ssr3@cornell.edu. in a more effective manner. However, to develop new cheese products with desired and consistent functional properties, it is necessary to devise new and reliable techniques to measure and evaluate the fundamental properties of the cheese. Consumer preference of Mozzarella is based on the meltability, stretchability, elasticity, free oil formation, and browning of the melted cheese (McMahon et al., 1993). Among these, stretchability, meltability, and elasticity are functional properties that are directly related to fundamental rheological properties. Stretchability is the most important characteristic when considering uses in various food formulations (Gunasekaran and Ak, 2003).

Typical tests to measure stretchability can be summarized as the fork test, imitative tensile stretch technique, instrumental vertical elongation method, and 3pronged hook probe test. The fork test (McMahon, 1996) is a popular technique where shredded cheese (240 to $360 \mathrm{~g}$ ) is placed on a pizza crust (20 to $36 \mathrm{~cm}$ in diameter) with sauce ( 60 to $150 \mathrm{~g}$ ) and baked (4 to $6 \mathrm{~min}$ at $160^{\circ} \mathrm{C}$ ). The baked product is allowed to sit for 30 to $60 \mathrm{~s}$ and then a fork is inserted into the cheese mass and is stretched in the upward direction. The length of the cheese strands at failure is taken as a measure of stretchability. Despite the guidelines, uncontrolled temperature during stretching, variations in direction and speed of stretching, and sample size yield subjective results that are suitable to assess sample-to-sample comparison at the same location.

Attempts have also been made to use objective instrumental techniques to measure cheese stretchability. The imitative tensile stretch technique (Apostolopoulos, 1994) is an instrumental technique where a standard weight of shredded cheese is placed on a pizza crust and heated in a microwave oven for $15 \mathrm{~s}$. A circular plate from the center of the crust is cut and attached to the crosshead of a uniaxial testing machine. This plate is pulled vertically at a constant rate of $25 \mathrm{~mm} /$ $\mathrm{s}$, and the distance when all of the cheese strands fail upon elongation is taken as a measure of stretchability. A similar technique is the vertical elongation method (Gunasekaran and Ak, 2003) in which shredded cheese in a petri dish is placed in a water bath that provides temperature control. A T-bar attached to the crosshead 
Table 1. Stretch lengths for 2 commercially available brands of sliced Mozzarella cheese with different expiration dates.

\begin{tabular}{lllllll}
\hline $\begin{array}{l}\text { Sample } \\
\text { code }\end{array}$ & $\begin{array}{l}\text { Time to } \\
\text { expiry }(\mathrm{d})\end{array}$ & $\begin{array}{l}\text { Observations } \\
(\mathrm{n})\end{array}$ & $\begin{array}{l}\text { Mean sample } \\
\text { weight } \\
(\mathrm{kg})\end{array}$ & $\begin{array}{l}\text { Mean sample } \\
\text { thickness } \\
(\mathrm{m})\end{array}$ & $\begin{array}{l}\text { Mean stretch } \\
\text { length } \\
(\mathrm{m})\end{array}$ & $\begin{array}{l}\text { Stretch rate at } \\
\text { failure }(\mathrm{m} / \mathrm{s})\end{array}$ \\
\hline A-45 & 45 & 15 & 0.0083 & 0.002 & $0.04 \pm 0.006^{\mathrm{a}}$ & 0.0026 \\
$\mathrm{~A}-55$ & 55 & 11 & 0.0087 & 0.002 & $0.05 \pm 0.005^{\mathrm{bc}, \mathrm{x}}$ & 0.0013 \\
$\mathrm{~B}-79$ & 79 & 10 & 0.0133 & 0.003 & $0.06 \pm 0.013^{\text {bc, }}$ & 0.0055 \\
B-124 & 124 & 10 & 0.0134 & 0.003 & $0.07 \pm 0.013^{\mathrm{bc}, \mathrm{z}}$ & 0.0036 \\
B-140 & 140 & 10 & 0.0134 & 0.003 & $0.09 \pm 0.019^{\mathrm{d}}$ & 0.0029 \\
\hline
\end{tabular}

${ }^{\mathrm{a}, \mathrm{d}}$ Significantly different $(P<0.01)$ according to ANOVA-Tukey pairwise comparison test.

${ }^{\mathrm{b}, \mathrm{c}}$ Not significantly different $(0.05<P<0.1)$ according to ANOVA-Tukey pairwise comparison test.

${ }^{\mathrm{x}, \mathrm{y}, \mathrm{z}}$ Significantly different $(P<0.05)$ according to 2 -group $t$-test.

of a uniaxial testing machine is immersed inside the cheese shreds, and, upon melting, the cheese is stretched at a constant deformation rate. The stretch profile is recorded to analyze the peak force, failure strain, and toughness. In a recent modified tensile test method (Fife et al., 2002), a 3-pronged hook probe is used instead of the T-bar. In addition to peak force and failure strain, stretch quality, defined as the mean force exerted to elongate cheese strands from 5 to $20 \mathrm{~cm}$, is extracted from the stretch profile. The major drawback of all of these techniques is the lack of control on moisture loss and temperature during stretch; thus, the results are not very reproducible.

One of the objective methods proposed to measure cheese stretchability is the fiber-spinning technique (Cavella et al., 1992) originally developed by Petrie (1979) to assess the spinnability of polymeric melts in which the strength of a thin string of melted cheese is measured as it is extruded through a capillary. Although the method is capable of measuring the failure stress and strain values directly in a temperature- and moisture-controlled medium, it is hard to adopt in an industrial setting. A method proposed by Ak and Gunasekaran (1995a) provides control on moisture loss and partial control on temperature during measurement of stretch properties in which a chunk of cheese immersed in an oil bath stretches under its own weight or under the influence of a pulling weight. The stretch experiment takes place under the effect of an unsteady state temperature profile. Therefore, the stretch rate and stretch length are measured under the interactive influence of the pulling weight and the temperature profile. Beyond these two factors, a chunk of cheese is also prone to contain inherent microscopic defects because of its grain structure, which is expected to further complicate the measurement and assessment of stretch characteristics.

The objective of this investigation was to test a reproducible and reliable technique for practical use to measure and quantify cheese stretchability. Our proposed technique is based on the principle of the Ring-andBall test (ASTM, 1993; Designation D 36 to 95) used to measure the softening point of polymers. This method provides control on moisture loss and temperature during stretch by immersing the entire set-up in a mineral oil bath and by using a thin cheese slice. Stretch length at failure was taken as the measure of stretchability. Extensional viscosity of melted cheese was estimated from the stretch length vs. time data. Reproducibility of the method was assessed based on its ability to predict differences in age and brand.

\section{MATERIALS AND METHODS}

\section{Sample Preparation}

Two different brands of commercially available sliced Mozzarella were locally purchased. Assessment of the sensitivity of the method to differences in age was based on the number of days to expiry. Cheese slices were examined under light, and $6 \times 6 \mathrm{~cm}^{2}$ samples with no observable defects, such as large holes, were cut from the center of the slices using a sharp knife. Sample weight and thickness were recorded (Table 1).

\section{Stretchability Apparatus}

The apparatus (Figure 1) devised to measure stretchability consisted of a glass container (height $=47 \mathrm{~cm}$; diameter $=30.5 \mathrm{~cm}$ ) filled with mineral oil (Crystal Plus Oil 70FG) up to a height of $42 \mathrm{~cm}$, a circulating heater, an inverted glass cone (height $=38 \mathrm{~cm}$; top diameter $=$ $3.6 \mathrm{~cm}$; bottom diameter $=11.8 \mathrm{~cm}$ ) with $1-\mathrm{cm}$ scale calibration markings down the slanted side, a wire mesh basket $\left(15.2 \times 15.2 \times 15.2 \mathrm{~cm}^{3}\right)$ with handles, a hollow circular plastic cheese holder (i.d. $=3.6 \mathrm{~cm}$; o.d. $=$ $6.4 \mathrm{~cm}$; height $=1.8 \mathrm{~cm}$ ) with 5 steel pins (height $=4$ $\mathrm{mm}$ ), a hollow circular plastic cheese support (i.d. $=3.4$ $\mathrm{cm}$; o.d. $=14.4 \mathrm{~cm}$; thickness $=3 \mathrm{~mm}$ ) with 5 indentations, a ball centering funnel (top diameter $=4.5 \mathrm{~cm}$; bottom diameter $=1.5 \mathrm{~cm}$ ), and a spherical iron ball. 


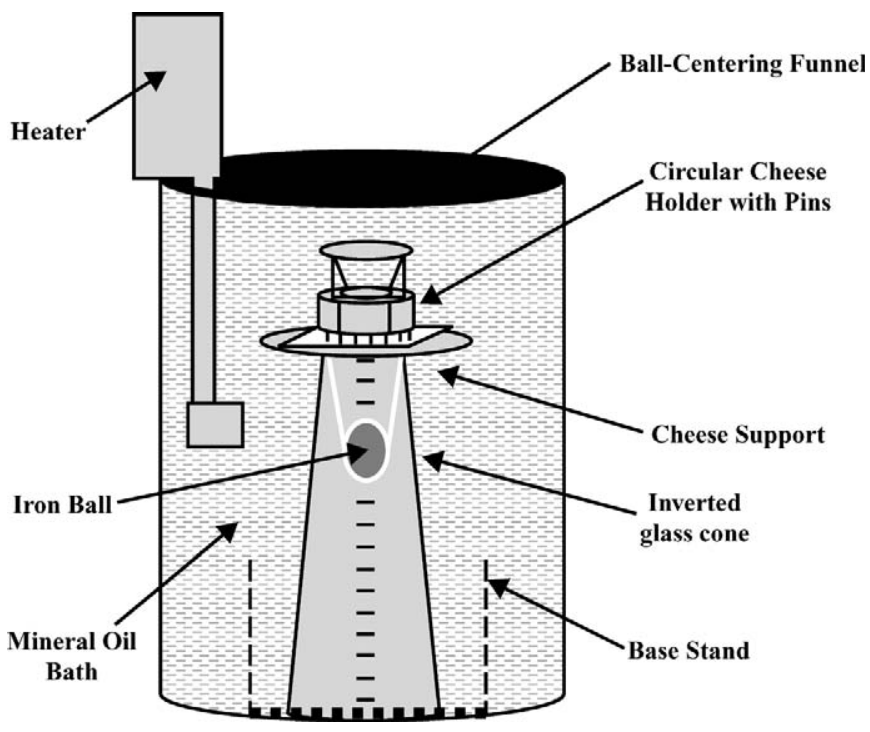

Figure 1. Schematic of the stretch apparatus used in this study.

Characteristics of the iron ball and the mineral oil are listed in Table 2.

A recirculation heater was used to keep the mineral oil at a temperature of $65^{\circ} \mathrm{C}$ to assure melting of the cheese sample. The inverted glass cone was placed inside the wire mesh basket, and the bottom of the basket was covered with a piece of non-stick aluminum foil. The glass cone and the basket were immersed into the mineral oil bath. The glass cone had 6 small slits, 2 $\mathrm{mm}$ in thickness, at regular intervals for the air to escape while inserting it into the bath. The cheese sample was placed on the hollow circular support. The circular cheese holder was placed on top of the cheese slice with the steel pins facing downward to hold the cheese in place. The steel pins were matched up with the indentations in the cheese support. This 3-layer section was placed on the top of the inverted cone in the oil bath. The ball-centering funnel was placed on top of the circular cheese holder. The iron ball was then placed in the funnel to center it on the cheese slice. The cheese sample softened and started to stretch under the weight of the iron ball.

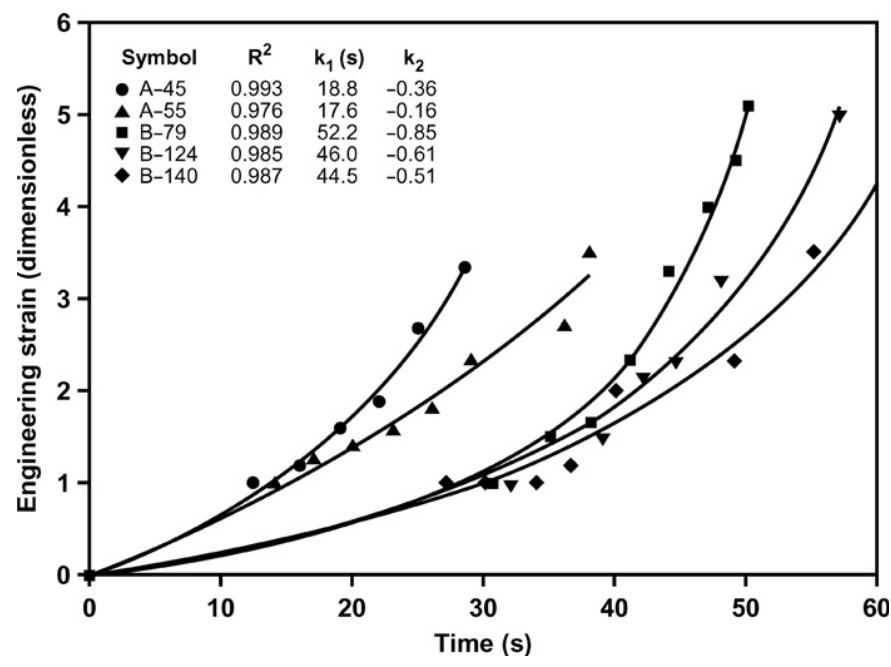

Figure 2. Engineering strain $\left(\frac{\mathrm{L}-\mathrm{L}_{0}}{\mathrm{~L}_{0}}\right)$ vs. time data for cheese samples with different expiration dates. $\mathrm{k}_{1}$ and $\mathrm{k}_{2}$ are parameters of Eq. [1].

Stretch length vs. time data was taken by recording the time corresponding to each $1 \mathrm{~cm}$ stretch for the first $0.05 \mathrm{~m}$, as well as the time of failure, and was averaged over the number of observations. Figure 2 represents data points with $< \pm 10 \%$ error. The vertical length of stretch until failure of all of the cheese strands was reported as the measure of stretchability. Stretch length vs. time data was expressed in terms of engineering strain, $\left(\mathrm{L}-\mathrm{L}_{0}\right) / \mathrm{L}_{0}$, where $\mathrm{L}(\mathrm{cm})$ is the stretch length at any time $t$ and $L_{0}=0.01 \mathrm{~m}$ is the stretch length at the beginning of data acquisition. Engineering strain vs. time data was expressed as (Peleg, 1980)

$$
\frac{\mathrm{L}-\mathrm{L}_{0}}{\mathrm{~L}_{0}}=\frac{\mathrm{t}}{\mathrm{k}_{1}+\mathrm{k}_{2} \mathrm{t}}
$$

Constants $\mathrm{k}_{1}$ and $\mathrm{k}_{2}$ were evaluated by regression analysis.

Table 2. Characteristics of the ball and mineral oil.

\begin{tabular}{llllc}
\hline & & & Mathematical & \\
Material & Characteristic & Symbol & expression & Value \\
\hline Iron ball & Mass $(\mathrm{kg})$ & $\mathrm{m}_{\mathrm{b}}$ & None & $5.6 \times 10^{-3}$ \\
& Diameter $(\mathrm{m})$ & $\mathrm{D}_{\mathrm{b}}$ & None & $1.1 \times 10^{-2}$ \\
& Volume $\left(\mathrm{m}^{3}\right)$ & $\mathrm{V}_{\mathrm{b}}$ & $\pi \mathrm{D}_{\mathrm{b}}^{3} / 6$ & $7.0 \times 10^{-7}$ \\
& Projected $\mathrm{area}\left(\mathrm{m}^{2}\right)$ & $\mathrm{A}$ & $\pi \mathrm{D}_{\mathrm{b}}^{2} / 4$ & $9.5 \times 10^{-5}$ \\
Mineral oil & Density $\left(\mathrm{kg} / \mathrm{m}^{3}\right)$ & $\rho_{\text {oil }}$ & None & 860 \\
& Viscosity $(\mathrm{kg} / \mathrm{m} \cdot \mathrm{s})$ & $\mu_{\text {oil }}$ & None & $1 \times 10^{-2}$ \\
\hline
\end{tabular}




\section{Evaluation of Extensional Viscosity}

Stretch length vs. time data obtained during the stretch experiment was converted into strain vs. time data, where Hencky strain $(\varepsilon)$ is defined as

$$
\mathrm{d} \varepsilon=\frac{\mathrm{dL}}{\mathrm{L}} \text { and thus } \varepsilon_{\mathrm{i}}=\ln \left(\frac{\mathrm{L}}{\mathrm{L}_{\mathrm{i}}}\right) .
$$

$\mathrm{L}_{\mathrm{i}}$ and $\mathrm{L}$ are the stretch lengths at the beginning and end of any time interval $\Delta \mathrm{t}$. Therefore, strain at any time $t,\left(\left.\varepsilon\right|_{t}\right)$ during the stretch experiment was calculated as

$$
\left.\varepsilon\right|_{t}=\sum_{i=1}^{n} \varepsilon_{t} .
$$

Stress $(\sigma)$ applied on the cheese mass was calculated from the equation

$$
\sigma=\frac{\sum \mathrm{F}}{\mathrm{A}}
$$

where $\sum F$ is the summation of the forces applied and $\mathrm{A}$ is the projected area of the spherical ball (Table 2). $\left.\mathrm{L}_{0}\right|_{\mathrm{t}=0}=0.01 \mathrm{~m}$ assures that data collected correspond to small conical angles and that the force is applied on the projected area where $\mathrm{L}_{0}$ is greater than the radius of the spherical ball. Summation of forces $\left(\sum F\right)$ applied is given by the following equation:

$$
\sum \mathrm{F}=\left(\mathrm{m}_{\mathrm{b}}+\mathrm{m}_{\mathrm{c}}\right) g-\left(\mathrm{V}_{\mathrm{b}}+\mathrm{V}_{\mathrm{c}}\right) \rho_{\text {oil }} \mathrm{g},
$$

where $\mathrm{g}$ is the acceleration caused by gravity, $\mathrm{m}_{\mathrm{b}}$ and $\mathrm{V}_{\mathrm{b}}$ are the mass and volume of the ball (Table 2), and $\mathrm{m}_{\mathrm{c}}$ and $\mathrm{V}_{\mathrm{c}}$ are the mass and volume of the cheese sample (Table 1), respectively. The first term in Eq. [5] is the gravitational force, and the second term is the buoyancy force, where the cheese mass extends under its own weight and the weight of the ball (Table 2). Drag force, which is proportional to the square of the rate of stretch $(\mathrm{dL} / \mathrm{dt})$, calculated from Eq. [1] varied between $5.0 \times$ $10^{-4}$ and $2.6 \times 10^{-3} \mathrm{~m} / \mathrm{s}$ for the lot tested for Brand A and between $2.0 \times 10^{-4} \mathrm{~m} / \mathrm{s}$ and $5.5 \times 10^{-3} \mathrm{~m} / \mathrm{s}$ for the lot tested for Brand $\mathrm{B}$, and its contribution to the overall force was negligibly small $\left(<1 \times 10^{-5} \mathrm{~N}\right)$. A similar argument was also valid for the contribution of $\mathrm{d}^{2} \mathrm{~L} / \mathrm{dt}^{2}$ term calculated from the second derivative of Eq. [1] $(<1 \times$ $10^{-5} \mathrm{~N}$ ). Hydrostatic effects were negligible as well when compared with the contribution of gravitational and buoyancy forces $\left(7.0 \times 10^{-2}\right.$ to $7.4 \times 10^{-2} \mathrm{~N}$ for Brand A and $8.9 \times 10^{-2} \mathrm{~N}$ for Brand $\mathrm{B}$ ).

Extensional viscosity $\left(\eta_{\mathrm{E}}\right)$ was then calculated from the equation

$$
\eta_{\mathrm{E}}=\frac{\sigma}{\dot{\varepsilon}}
$$

where $\sigma$ is the stress applied by the ball on the cheese mass and $\dot{\varepsilon}$ is the strain rate calculated from the slope of the Hencky strain vs. time data by linear regression.

\section{Statistical Analysis}

The stretch lengths of 5 groups of samples $(45,55$, 79,124 , and $140 \mathrm{~d}$ to expiry) were compared by ANOVA-Tukey pairwise comparison test (SYSTAT 7.0 for Windows). Groups with $P<0.05$ were considered to be significantly different from each other. Samples with $0.05<P<0.1$ were further compared with each other by the 2 -group $t$-test based on separate $t$ values (SYSTAT 7.0 for Windows), and $P<0.05$ indicated significant difference between the group pairs.

\section{RESULTS AND DISCUSSION}

\section{Stretchability}

The stretch apparatus devised and used to measure the stretch length of Mozzarella cheese effectively produced stretch data at a constant temperature with no apparent moisture loss. As expected, the stretch length decreased with age. It is known that Mozzarella does not need a ripening period, but 2 - to 3 -wk refrigerated storage leads to a desirable decrease in elasticity and increase in meltability (Kinstedt, 1991), which is expected to cause a decrease in stretchability as well. The objective measure of stretchability in the present study was the observed stretch length. Within the variability of the system, comparison of the samples with respect to their age showed that the youngest cheese $(140 \mathrm{~d}$ to expiry) and the oldest cheese ( $45 \mathrm{~d}$ to expiry) were significantly different from each other and the rest of the samples (Table 1). Group comparisons for the intermediate age groups (55, 79, and $124 \mathrm{~d}$ to expiry) showed that these samples also differed from each other within the limits of their group variability (Table 1). Therefore, it was possible to discriminate the stretch length of the cheese samples with respect to their age objectively by using the technique proposed in the present study. However, the 2 commercial brands could not be compared with respect to their stretch lengths because it was not possible to find samples of different brands with similar expiration dates and thicknesses.

Stretch length results obtained with the proposed method were lower than those obtained in the vertical elongation test $(0.177 \pm 0.016 \mathrm{~m}$ at a stretch rate of 3.3 $\times 10^{-3} \mathrm{~m} / \mathrm{s}$ and $0.186 \pm 0.015 \mathrm{~m}$ at a stretch rate of 8.3 $\times 10^{-3} \mathrm{~m} / \mathrm{s}$ ) (Gunasekaran and Ak, 2003). It was ob- 
served from the data by Gunasekaran and Ak (2003) that an increase in the stretch rate leads to an increase in the stretch length. Stretch length values for the uniaxial extension apparatus in which a chunk of cheese stretched under the effect of its own weight and a pulling weight have not been reported (Ak and Gunasekaran, 1995a). Data obtained by Gunasekaran and Ak (2003) represent the results of tensile tests at constant stretch rates, and the proposed method provides the application of an instantaneous constant stress on the cheese sample, thus fulfilling the conditions for a creep test where the relationship between the stretch length and time is nonlinear (Figure 2). The model parameters (Figure 2) indicated that the stretch rates (dL/dt) calculated from Eq. [1] varied between $5.0 \times 10^{-4}$ and $2.6 \times$ $10^{-3} \mathrm{~m} / \mathrm{s}$ for Brand A and $2.0 \times 10^{-4}$ and $5.5 \times 10^{-3} \mathrm{~m} / \mathrm{s}$ for Brand B during the stretch experiments. Stretch rates in the order of magnitude of the vertical elongation test were reached towards failure of the cheese strands (last 10s of stretch) during the experiment described by the proposed method.

Thicknesses and, thus, weights of the 2 commercially available brands of sliced Mozarella cheese were different (Table 1). Therefore, the creep test took place under the effect of different forces applied for the 2 brands. The force applied on Brand B was higher than that on Brand A, because Brand B samples had a higher weight attributable to larger thickness (Table 1). Parameters of the Peleg (1980) model showed that absolute values of $\mathrm{k}_{1}$ and $\mathrm{k}_{2}$ increased with aging for both brands (Figure 2 ), where $1 / \mathrm{k}_{1}$ refers to the initial decay and $1 / \mathrm{k}_{2}$ refers to the asymptotic value. A decrease in $1 / \mathrm{k}_{1}$ with age indicated that the cheese yields more easily to the applied stress as it ages, and a decrease in $1 / \mathrm{k}_{2}$ indicated a higher stretch rate, thus, flowability. This is an expected result because molecular degradation caused by proteolysis during aging causes the strength of the cheese to decrease. Conversely, although Brand B samples had a longer time to expiry, they also had higher $\mathrm{k}_{1}$ and $\mathrm{k}_{2}$ values. Brand $\mathrm{B}$ yielded to the applied force more easily, as its higher weight caused it to creep under the weight of the ball, making initial decay faster $\left(1 / k_{1}\right)$. Conversely, its approach to failure was slower $\left(1 / \mathrm{k}_{2}\right)$. Thus, it is reasonable to assume that $\mathrm{k}_{2}$ reflects age-related stretch characteristics.

\section{Extensional Viscosity}

Stretch length vs. time data was further analyzed in terms of more fundamental quantities, such as strain rate and melt viscosity. The proposed stretch apparatus was also able to provide data on fundamental rheological properties of Mozzarella in addition to being an objective measure of stretchability. Hencky strain,
Eq.[2], vs. time data obtained from the stretch length vs. time data showed that data after a $0.01-\mathrm{m}$ stretch had a constant slope; thus, the cheese melt responded as a viscous liquid to the stress applied by the ball and deformed under its own weight and the weight of the ball as opposed to the buoyancy of the oil (Eq. [5]). Strain rates (Table 3) calculated by linear regression $\left(\mathrm{R}^{2}=0.99\right)$ of the Hencky strain vs. time data showed that differences in $\mathrm{k}_{1}$ and $\mathrm{k}_{2}$ values were related to the strain rate, and the strain rate is also sensitive to age and brand differences. In general, strain rate increased with the age of the cheese, which is reflected by $\mathrm{k}_{2}$ values (Figure 2). Brand $B$ stretched at a greater strain rate than Brand $\mathrm{A}$, giving higher $\mathrm{k}_{1}$ and $\mathrm{k}_{2}$ values.

Extensional viscosity values evaluated by using the information on strain rates, Eq. [6], for the cheese samples tested varied from $13.6 \mathrm{kPa} \cdot \mathrm{s}$ for the oldest cheese to $17.4 \mathrm{kPa} \cdot \mathrm{s}$ for the youngest cheese (Table 3). Brand differences in weight and thickness of the samples did not influence the extensional viscosity results. Thus, data obtained from the stretch apparatus were also sensitive enough to provide extensional viscosity data. Extensional viscosity of the cheese samples decreased with age, as expected, which is in accordance with the stretch length results.

Although extensional viscosities obtained in the present study seem to be lower than those obtained in the previous studies (Table 3), a one-to-one comparison was not possible because of the differences in the techniques used, the test temperature, and the strain rates involved. Extensional viscosities of cheeses have generally been measured by the lubricated squeezing flow technique, which in fact measures viscosity under biaxial extension. It is known that for Newtonian fluids, biaxial extensional viscosity is twice as much as the uniaxial extensional viscosity. The same relationship is also true between the apparent uniaxial and biaxial extensional viscosities of a non-Newtonian viscous liquid at low strain rates. It is known that cheeses show non-Newtonian, strain-rate thinning behavior in which apparent viscosity decreases with respect to strain rate according to a power law relationship. Also, the wellknown Arrhenius relationship dictates that, for viscous liquids, viscosity decreases exponentially with an increase in temperature. The strain rates obtained in the present study ( 0.052 to $0.061 / \mathrm{s}$ ) (Table 3 ) lie in between the biaxial strain rates covered in previous studies (0.015 and 0.15/s) (Ak and Gunasekaran, 1995b). As an order of magnitude estimate, the apparent biaxial extensional viscosity corresponding to the strain rates of 0.05 and $0.06 / \mathrm{s}$ of the stretch experiment is expected to be $\approx 65$ and $55 \mathrm{kPa} \cdot \mathrm{s}$, assuming the cheese melt behaves as a power law fluid. Considering that the stretch experiment is a uniaxial experiment, the viscosity val- 
Table 3. Extensional viscosity values for 2 commercial brands of sliced Mozzarella cheese and comparison with literature values.

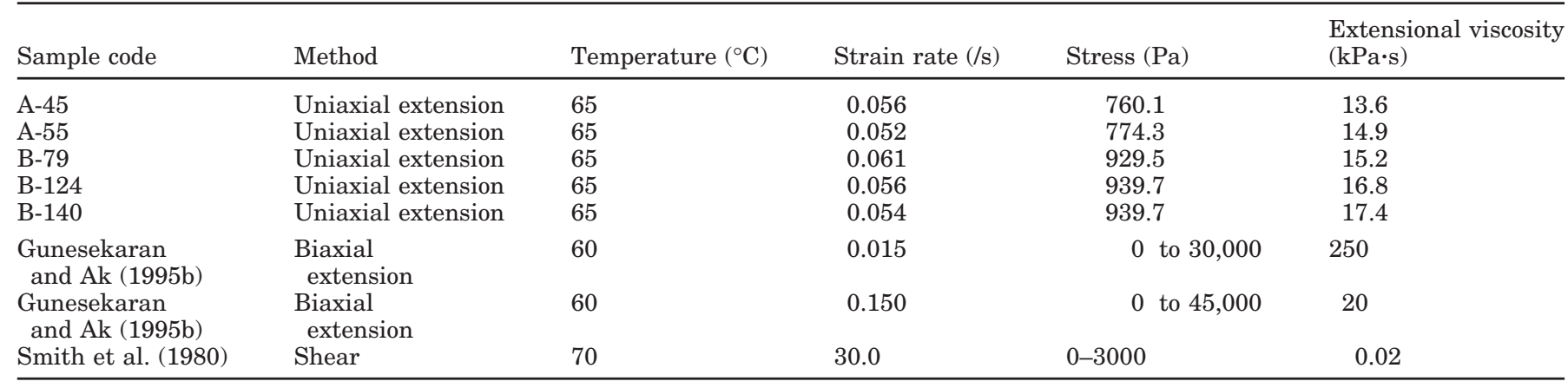

ues should be expected to be between 25 and $30 \mathrm{kPa} \cdot \mathrm{s}$. However, it was not possible to assess the effect of temperature at the strain rates corresponding to the stretch experiment, as $60^{\circ} \mathrm{C}$, which corresponds to the highest temperature used during biaxial extension experiments in previous studies, is lower than the temperature of the stretch experiment $\left(65^{\circ} \mathrm{C}\right)$. Extensional viscosities obtained from the stretch experiment could not be compared with shear viscosity results available at $70^{\circ} \mathrm{C}$ in the literature because of a very different strain rate range (10 to $10,000 / \mathrm{s}$ ) covered in shear viscosity measurement by Smith et al. (1980). However, it is evident that temperature and shear rate have an interactive effect on apparent viscosity, and temperature becomes more influential as shear rate decreases (Smith et al., 1980).

One of the advantages of using the proposed stretch apparatus as a means of evaluating the extensional viscosity is that stretch is a free-boundary phenomenon in which the cheese extends under its own weight and the weight of the ball as opposed to the buoyancy of the mineral oil. Thus, fat phase separation and wall slip do not interfere with the viscosity results. The ability to observe the expected strain rate-thinning behavior of Mozzarella and the capability of the method to implement age-related differences in stretch length and extensional viscosity show that the stretch experiment provides the conditions for an objective uniaxial extension test.

\section{CONCLUSIONS}

The new stretch apparatus and the test procedure described here gave reproducible stretch lengths for samples from the same batch of cheese by eliminating the influences of moisture loss and change in temperature during the test. The method successfully discriminated between age- and brand-related differences in stretchability of Mozzarella cheese. The stretch length vs. time data obtained during the free-boundary stretch test also allowed assessments of age- and brand-related differences in stretch rate, strain rate, and extensional viscosity of the test samples. This technique also offers the possibility of measuring the uniaxial extensional viscosity of cheese samples without interference from phase separation and wall slip effects.

\section{REFERENCES}

Ak, M. M., and S. Gunasekaran. 1995a. Measuring elongational properties of Mozzarella cheese. J. Texture Stud. 26:147-160.

Ak, M. M., and S. Gunasekaran. 1995b. Evaluating rheological properties of Mozzarella cheese by the squeezing flow method. J. Texture Stud. 26:695-711.

American Society for Testing and Materials (ASTM). 1993. Annual Book of ASTM Standards. Vol. 04.04, ASTM, West Conshohoken, PA.

Apostolopoulos, C. 1994. Simple empirical and fundamental methods to determine objectively the stretchability of Mozzarella cheese. J. Dairy Res. 61:405-413.

Cavella, S., S. Chemin, and P. Masi. 1992. Objective measurement of the stretchability of Mozzarella cheese. J. Texture Stud. 23:185-194.

Fife, R. L., D. J. Mc Mahon, and C. J. Oberg. 2002. Test for measuring the stretchability of melted cheese. J. Dairy Sci. 85:3549-3556.

Gunasekaran, S., and M. M. Ak. 2003. Measuring cheese stretchability. Pages 377-397 in Cheese Rheology and Texture. CRC Press, Boca Raton, FL.

International Dairy Foods Association (IDFA). 2002. Pages 11 and 29 in Cheese Facts. 2002 ed. IDFA, Washington, DC.

Kinstedt, P. 1991. Functional properties of Mozzarella cheese on pizza: A review. J. Cult. Dairy Prod. 26:27-31.

Kinstedt, P. 1993. Effect of manufacturing factors, composition, and proteolysis on the functional characteristics of Mozzarella cheese. CRC Food Sci. Nutr. 33:167-187.

Mc Mahon, D. J. 1996. Measuring Stretch of Mozzarella Cheese. Page 19 in Proc. 12th Biennial Cheese Ind. Conf., Utah State University, Logan.

Mc Mahon, D. J., C. J. Oberg, and W. McManus. 1993. Functionality of Mozzarella cheese. Aust. J. Dairy Sci. 48:99-104.

Peleg, M. 1980. Linearization of relaxation and creep curves of solid biological materials. J. Rheol. 24:451-463.

Petrie, C. J. S. 1979. Elongational Flow: Aspects of the Behavior of Model Electroviscous Fluids. Pitman, London.

Smith, C. E., J. R. Rosenau, and M. Peleg. 1980. Evaluation of the flowability of melted Mozzarella cheese by capillary rheometry. J. Food Sci. 45:1142-1145. 